\title{
CrimRxiv
}

\section{Suicidal Fragility of Young Offenders. Phenomenological Interpretative Analysis of Custody Experience}

Laurie St-Pierre, Catherine Laurier

Published on: Mar 03, 2022

DOI: $10.21428 / \mathrm{cb} 6 \mathrm{ab} 371.6 \mathrm{e} 0586 \mathrm{c} 3$

License: Creative Commons Attribution 4.0 International License (CC-BY 4.0). 
